\title{
Patterns of variations in large pelagic fish: A comparative approach between the Indian and the Atlantic Oceans
}

\author{
A. Corbineau ${ }^{a}$, T. Rouyer ${ }^{\text {b, c }}$, J.-M. Fromentin ${ }^{b}$, B. Cazelles ${ }^{\text {d, e, }}$ A. Fonteneau ${ }^{a}$ and F. Ménard ${ }^{a,{ }^{*}}$
}

a IRD, UMR 212 EME (Exploited Marine Ecosystems), Centre de Recherche Halieutique Méditerranéen et Tropical, Avenue Jean Monnet, BP 171, 34203 Sète cedex, France

${ }^{\mathrm{b}}$ IFREMER, UMR 212 EME (Exploited Marine Ecosystems), Centre de Recherche Halieutique Méditerranéen et Tropical, Avenue Jean Monnet, BP 171, 34203 Sète cedex, France

${ }^{c}$ Centre for Ecological and Evolutionary Synthesis, Department of Biology, University of Oslo, P.O. Box 1066 Blindern, N-0316 Oslo, Norway

${ }^{\mathrm{d}}$ CNRS UMR 7625, ENS, 46 rue d'Ulm, 75230 Paris cedex 05, France

e IRD, UR 079 GEODES, 32 Avenue Henri Varagnat, 93142 Bondy cedex, France

\author{
*: Corresponding author : F. Ménard, Tel.: +33 4995732 30; fax: +33 49957 32 95, email address : \\ frederic.menard@ird.fr
}

\begin{abstract}
:
Catch data of large pelagic fish such as tuna, swordfish and billfish are highly variable ranging from short to long term. Based on fisheries data, these time series are noisy and reflect mixed information on exploitation (targeting, strategy, fishing power), population dynamics (recruitment, growth, mortality, migration, etc.), and environmental forcing (local conditions or dominant climate patterns). In this work, we investigated patterns of variation of large pelagic fish (i.e. yellowfin tuna, bigeye tuna, swordfish and blue marlin) in Japanese longliners catch data from 1960 to 2004. We performed wavelet analyses on the yearly time series of each fish species in each biogeographic province of the tropical Indian and Atlantic Oceans. In addition, we carried out cross-wavelet analyses between these biological time series and a large-scale climatic index, i.e. the Southern Oscillation Index (SOI). Results showed that the biogeographic province was the most important factor structuring the patterns of variability of Japanese catch time series. Relationships between the SOI and the fish catches in the Indian and Atlantic Oceans also pointed out the role of climatic variability for structuring patterns of variation of catch time series. This work finally confirmed that Japanese longline CPUE data poorly reflect the underlying population dynamics of tunas.
\end{abstract}

Keywords: large pelagic fish, time-series analysis, wavelet analysis, Southern Oscillation Index, fisheries, Indian Ocean, Atlantic Ocean. 


\section{Introduction}

Abundance of large pelagic fish, such as tuna and billfish, are known to fluctuate extensively over a large range of spatial and temporal scales (Ravier and Fromentin, 2001; Lehodey et al., 2006). Environmental variability is known to shape the spatial distribution, migration patterns and population dynamics of large pelagic fish (Polovina, 1996; Lehodey et al., 1997; Ravier and Fromentin, 2004), but also to modify the dynamics and the catchability of the fleet targeting these species (Ward and Hindmarsh, 2007). Fishing activity through the removal of top predators further alters the food-web structure and can change population demography (Jennings and Kaiser, 1998; Essington et al., 2002). In addition, several studies recognized the importance of biological processes, such as biotic interactions, and how they impact fluctuations in fish stocks (Myers and Cadigan, 1993; Fromentin et al., 2001). Understanding the underlying reasons for the variability of large fish predators is a complex issue that can be addressed by analysing long time series of commercial catches. Such time series are typically noisy, often strongly non-stationary and contain mixed information on environmental forcing, population dynamics and exploitation (Rouyer et al., 2008a).

In this paper, we try to address these questions by investigating patterns of variation of different tuna species and tuna-like species exploited in the Atlantic and Indian Oceans. Such an approach has been already conducted in the Atlantic Ocean (Rouyer et al., 2008a) and in the Indian Ocean (Corbineau et al., 2008), separately but this study is the first attempt to analyze and compare patterns of variation of catch time series data of large pelagic fishes in these two oceans, using an identical source of data (from the Japanese longliners). Each oceanic basin was divided in biogeographic provinces (Longhurst, 2007) and we selected four species (yellowfin tuna, Thunnus albacares; bigeye tuna, Thunnus obesus; swordfish, Xiphias gladius; and blue marlin, Makaira mazara in the Indian Ocean and M. nigricans in the Atlantic Ocean) for which we have data in a long time series. Wavelet analyses were performed on each yearly time series to describe temporal patterns of variation (Cazelles et al., 2008), and comparisons were made according to the similarities among wavelet spectra (Rouyer et al., 2008b). Variations in tuna catch rates are often associated with large-scale climate indices, such as the Indian Oscillation Index in the Indian Ocean (Ménard et al., 2007; Corbineau et al., 2008). We, therefore, investigated cross-wavelets between tuna time series and the Southern Oscillation Index (SOI), considered here as the main climate index that impacts the world's oceans (Trenberth, 1984).

\section{Materials and methods}

\subsection{Fishery data}

Since the 1950s, Japanese longline fishery data have been available as a $5^{\circ} \times 5^{\circ}$ grid and by month, from the Indian Ocean Tuna Commission database (IOTC, http://www.iotc.org) and from the International Commission for the Conservation of Atlantic Tuna (ICCAT, http://www.iccat.es). Japanese longline gear is composed of a midwater mainline suspended on buoys floating at the sea surface. Japanese longlines consist of about 3500 baited hooks, carrying 5 to 25 hooks between successive floats and fishing mostly in a depth range of about 25-300 m. In tropical waters, they are used by large longliners that primarily target yellowfin and bigeye tunas. Japanese longliners have continuously modified their gear and practices to improve fishing power and catchability of target species (Ward and Hindmarsh, 2007). For example, nylon monofilament leaders were substituted for wire leaders from natural fibres in the mid 1980s, and hook design and bait species have also evolved. The emergence of deep 
longlines in the early 1970s in the Indian Ocean, and in the late 1970s in the Atlantic Ocean, was an important change in fishing practices, with an increase in the number of hooks between floats.

Catch and effort time series have been associated with the Longhurst provinces (Longhurst, 2007; Fig. 1) in the same time period (from 1960 to 2004 in both oceans). We adopted the Longhurst's division in biogeographic provinces because they are based on biogeochemical properties due to primary production, nutrient dynamics and mixed layer depth that influence the distribution of top predators (Longhurst, 2007; Fonteneau, 1998). Also, several province boundaries correspond with changes in species dominance (Longhusrt, Pers. Comm.), and maps of tuna catches give confidence that the represented distributions are real and correspond to the biogeochemical provinces of Longhurst. We considered five tropical provinces in the Indian Ocean: the Indian South Subtropical Gyre province (ISSG), the Eastern Africa Coastal province (EAFR), and the Northwest Arabian Upwelling province (ARAB); for convenience, the original Indian Monsoon Gyres province of Longhurst was divided in a West sub-province (MONSW) and in an East sub-province (MONSE) according to the spatial patterns of environmental variables characterizing the Indian Ocean Dipole (Saji et al., 1999; Corbineau et al., 2008). In the tropical Atlantic Ocean, we adopted five provinces also: the North Atlantic Tropical Gyral Province (NATR), the Caribbean Province (CARB), the Western Tropical Atlantic Province (WTRA), the Eastern Tropical Atlantic Province (ETRA), and the South Atlantic Gyral Province (SATL). Because of their small sizes and close proximity to the African coast, data from the Eastern Canary Coastal Province (CNRY) and the Guinea Current Coastal Province (GUIN) were compiled with the NATR and ETRA provinces, respectively.

In each province, we have extracted time series of catch and nominal catch per unit of effort (CPUE) for four species: yellowfin tuna, bigeye tuna, swordfish, and blue marlin. Monthly catches were summed to obtain a yearly catch time series for each province. The aggregations by year allowed us to investigate patterns of interannual variation in each province. Missing values linked to the spatial dynamics of the fleet precluded the analysis of seasonal variations by province. Nominal CPUE by province and species were computed by averaging ratios of catch to the number of hooks (Walters, 2003). Several time series were non-informative and were removed from analyses. We obtained 34 catch time series and 34 CPUE time series characterized by three factors: species ( 4 modalities), provinces (10 modalities) and ocean ( 2 modalities).

\subsection{Climatic index}

The Southern Oscillation Index (SOI) is a measure of the large-scale fluctuations in air pressure occurring between the western and eastern tropical Pacific. The SOI is based on the difference between sea level pressure anomalies at Tahiti $\left(17^{\circ} \mathrm{S}-149^{\circ} \mathrm{W}\right)$ and Darwin $\left(12^{\circ} \mathrm{S}-130^{\circ} \mathrm{E}\right)$, combining the Southern Oscillation into one series (Trenberth, 1984). El Niño episodes occur during the negative phase of the Southern Oscillation, while La Niña episodes occur during the positive phase. The monthly SOI index was averaged to calculate a yearly time series.

\subsection{Time-series analysis}

Wavelet analysis performs a time-frequency decomposition of the signal, which permits the estimation of the spectral characteristics of the signal as a function of time and then the identification of different periodic components (Torrence and Campo, 1998; Cazelles et al., 2008). Transient dynamics or gradual changes of the periodic components of the signal can then be detected and this approach can be applied to non-stationary time series, such as fisheries data. The wavelet power spectrum (WPS) is represented on a 2D plot with observation time as the $\mathrm{x}$-axis and periods or frequencies as the $\mathrm{y}$-axis. The wavelet analysis can be 
extended to bivariate cases in order to analyze patterns of covariation of two signals. Time series were standardized before performing the wavelet analyses.

In order to compare patterns of variation between commercial catch time series, we clustered the wavelet spectra, as described in Rouyer et al. (2008b). This method is based on the Maximum Covariance Analysis that calculates the dissimilarities between all pairs of wavelet spectra. A distance matrix is then obtained and a cluster analysis is carried out in order to construct a dendrogram. In addition, we plotted the distances originated from the cluster using boxplots by extracting the distances regarding each factor (ocean, species and province), and each modality (yellowfin tuna, bigeye tuna, swordfish, blue marlin, Equatorial and Tropical Indian Ocean, Equatorial and Tropical Atlantic Ocean) from the dissimilarity matrix, in order to investigate the main effects. Wavelet cross-spectra (WCS) between each time series and the SOl were also compared using the same method.

\section{Results}

\subsection{Patterns of variations in catch time series}

The cluster dendrogram based on the catch time series displayed five groups according to the similarities among wavelet spectra (Fig. $2 A)$. The first group $\left(G_{1}\right)$ was dominated by yellowfin tuna of the Indian Ocean. The second group $\left(\mathrm{G}_{2}\right)$ combined all the Atlantic time series of the ETRA province and, in addition, swordfish prevailed in this group. $\mathrm{G}_{3}$ was a group of all the time series of the ARAB province (Indian Ocean). Fourteen time series were classified in $\mathrm{G}_{4}$ : Indian time series dominated, including all the series of the MONSE and MONSW provinces, except one. The last group $\left(G_{5}\right)$ is represented by the Atlantic time series only: the central provinces (WTRA, NATR and SATL) occurred in similar proportions.

No clear grouping by species was evident, while there was a clear effect of province. The boxplots of the dissimilarities among factors (Fig. 3A) confirmed that the province factor had the most structuring effect. This is shown by the lowest median of the intra-province boxplot (Fig. 3A). No differences occurred between inter- and intra-species dissimilarities. There was no clear grouping by oceans, but the Indian time series displayed higher similarities among themselves than the Atlantic time series. Additional boxplots were computed for the modalities of the species (Fig. 3B). No clear pattern emerged, except among bigeye tuna: the wavelet spectra of those time series were more similar regardless of the province. In others words, the variability that characterized the bigeye time series in all provinces were comparable. Because of the small number of time series in each province, we further grouped equatorial and tropical provinces of each ocean. For both oceans, equatorial regions displayed higher similarities than tropical ones, especially in the Indian Ocean (Fig. 3C).

\subsection{Catch time series and SOI}

We first performed a wavelet analysis of the SOI (Fig. 4). The WPS exhibited three disconnected significant bands: the first in the 3 to 4-year periodic modes from 1968 until 1973, a second band in the 4 to 6-year modes from 1974 until 1988, and third band around the 10 to14-year period from 1972 until 2004.

We then investigated the association between the SOI and the tuna catch time series by performing 34 wavelet cross-spectra (WCS). The clustering analysis tends to provide a dendrogram with more structure than the previous analysis; the global median of the distances for this cluster was $16 \%$ less than the first dendrogram (Fig. 2A and B). From this analysis, five groups can be discriminated. The first group $\left(G_{1}\right)$ is dominated by the CARB province, while $G_{2}$ 
grouped all the ARAB provinces. In $\mathrm{G}_{3}$, Atlantic provinces occurred more frequently (especially NATR and ETRA) than Indian provinces, and swordfish and bigeye tuna were the dominant species. $G_{4}$ grouped all the WCS of the MONSW province and of the MONSE province (except one). $\mathrm{G}_{5}$ combines bigeye tuna and blue marlin of the WTRA province of the Atlantic Ocean only. Once again, the dendrogram was structured primarily by the province factor. The boxplot of dissimilarities among the factors showed the same pattern as described in the previous section (Fig. 3A and D). However, the distances decreased substantially, confirming the structuring effect of the SOI. The boxplots by species modalities (Fig. 3E) showed that bigeye tuna and swordfish had more similar patterns of variation (a decrease of $33 \%$ and $25 \%$, respectively, compared to Fig. 3B). The boxplots by province modalities confirmed that the equatorial areas displayed higher similarities than tropical ones, especially in the Indian Ocean (Fig. 3F).

For illustrative purpose, wavelet cross-spectra of bigeye tuna catch time series with SOI are shown (Fig. 5). The WCS of the equatorial Indian Ocean were very close and only exhibited a pattern of covariation with the SOI in the 12 to16-year cycle, while the tropical Indian Ocean and the equatorial and tropical Atlantic Ocean further displayed, in most cases, a 3 to 4-year cycle.

\subsection{CPUE time series}

The same approach was performed with the CPUE time series. However, most of the catch rate time series exhibited a severe decline in the first part of the signal (mostly during the first ten to twenty years of the time series) followed by a slightly variable signal until the end of the series. Consequently, the core of the variability is due to this early decline and is translated by the wavelet analysis into a long-term signal (results not shown). Therefore, the comparison of patterns of variation is not informative and did not add any additional information.

\section{Discussion}

Here, we carried out a descriptive analysis for studying the relevant factors that structure patterns of variation in commercial time series of large pelagic fish in the Indian and Atlantic Oceans. We analyzed both catch data of several species and CPUE data from the Japanese longline fisheries. We believe that nominal CPUE data from the Japanese longline fishery present several intrinsic biases that preclude their use for providing relevant information on the patterns of variations of tuna and tuna-like species. The major problems associated with these data are: (i) the temporal trends of several CPUE time series exhibited successively a sharp decline and a flat signal; (ii) the relevance of the number of hooks as a measure of the fishing effort all along the time series, (iii) increasing fishing effort over the time period. Several authors have shown that sharp declines in the CPUE that occurs in the initial phase of the fishery (Myers and Worm, 2003) overestimated the real decline in abundance (Walters, 2003; Hampton et al., 2005; Maunder et al., 2006; Polacheck, 2006). During this initial phase, CPUE were high but total catches were low. In contrast, the substantial increase of the catch and effort that followed this period (end of 1970s) did not match subsequent declines in catch rates. Polacheck (2006) summarized this point as follow: "Intuitively, if catches of a given magnitude, resulted in large (e.g. 50-80\%) decline in stock sizes, the expectation would be that a subsequent doubling or tripling of catches should engender further large declines and not be sustainable". Independently of the underlying causes of these early declines, it is unlikely that these catch rates are representative or proportional to abundance. For instance, a local aggregation of fishing vessels in a productive area generate high catches, high levels of nominal fishing effort, 
but only moderate catch rates, although these high catches indicate high biomass in a given area. In addition, interactions among fishing vessels can disrupt the relationship between CPUE and local abundance, as illustrated theoretically by Gillis and Peterman (1998). Furthermore, nominal CPUE data are based on the available hook number by $5^{\circ} \times 5^{\circ}$ grid and by month. This aggregated measure of the nominal fishing effort of longliners may not reflect the real fishing effort and cannot take into account the changes in targeting practices (Bigelow et al., 2002; Fonteneau and Richard, 2003; Bach et al., 2006; Kleiber and Maunder, 2008). For instance, deepening the longlines has increased the total number of hooks and the catch rates of bigeye tuna, but at the same time decreasing the CPUE of blue marlin. In the same way, longline fleets have continuously modified their fishing gear and practices to improve fishing power and catchability of targeted species. These changes are known to break down the relationship between catch rates and abundance (Ward and Hindmarsh, 2007). In conclusion, we postulate that the fishing strategy of the Japanese longline fleet tends to smooth variations in catch rate while catch time series exhibit signals that allowed us to better address our initial goals.

The analysis of the catch time series showed that the province was the most obvious factor that influences patterns of variation of tuna and tuna-like species in the Indian and Atlantic Oceans. However, the variability of the catch time series was not related to species. These results agree with those of Rouyer et al. (2008a) who studied patterns of variation in tuna and billfish time series exploited by different fishing gears throughout the Atlantic, and with the results of Corbineau et al. (2008) who investigated the variability of Taiwanese and Japanese time series in the Indian Ocean. Thus, our results reinforce the key role of the biogeographical provinces of Longhurst in the distribution of top predators that represent the higher trophic level. Our study did not display any clear effect of ocean, as we expected, but nonetheless, we showed significant differences between equatorial and tropical regions in both oceans, especially for the Indian Ocean. This ocean, in contrast to the Atlantic Ocean, is closed in the North by Arabia and Asia, and, consequently is characterized by a specific ocean circulation related to the wind monsoon regime (Schott and McCreary, 2001). For instance, warm subsurface water masses accumulate in the north and are characterized by low oxygen concentrations (Tomczak and Godfrey, 1994).

All time series covaried with the Southern Oscillation Index, which seems to structure patterns of variation in the catch time series. The impact of the SOI was more evident at the province scale, especially in the equatorial provinces of both oceans. Equatorial areas of the world's oceans are known to exhibit a clear response to El Niño-Southern Oscillation (White and Cayan, 2000). For instance, in the equatorial Indian Ocean, MONSW, which is the main fishing area for yellowfin tuna and bigeye tuna (Fonteneau, 1997), displayed the highest similarities. Warm or cold events in this province drive changes in the mixed-layer depth with consequences impacting tuna's habitat and thus, their abundance and catchability. The NATR province of the Atlantic Ocean showed a strong relation with the SOI, mostly due to bigeye tuna and swordfish. In addition, the wavelet cross-spectra between the SOI and the bigeye tuna time series (Fig. 5) in the tropical provinces showed a 14-16-year periodic mode that corresponds to the dominant long-term fluctuations in tropical areas (Steele, 1985).

Our approach combined, for the first time, different tuna and tuna-like species in several areas from two oceanic basins to show that catch time series of different species from the same geographic area are more similar than catch time series of the same species in different geographic areas. The province factor appears to be the most important factor to take into account when analyzing fisheries catch data. Furthermore, our study also demonstrates the potential impact of large-scale climate variability, and confirmed that Japanese CPUE data poorly reflect the underlying processes that drive fluctuations in abundance of large pelagic fish (Rouyer et al., 2008a). 


\section{Acknowledgements}

The authors gratefully thank F. Marsac for many helpful discussions and very thoughtful comments on the manuscript. This work, a part of the THETIS programme of the IRD (Institut de Recherche pour le Développement), is also supported by the REMIGE project funded by Agence Nationale de la Recherche (ANR 2005 Biodiv-011). AC was supported by a grant from Département Soutien et Formation, Institut de Recherche pour le Développement.

\section{References}

Bach, P., Travassos, P.D. Gaertner, D., 2006. Why the number of hooks per basket (HPB) is not a good proxy indicator of the maximum fishing depth in drifting longline fisheries? Collective Volume Scientific Papers ICCAT 59, 701-715.

Bigelow, K.A., Hampton, J., Miyabe, N., 2002. Application of a habitat-based model to estimate effective longline fishing effort and relative abundance of Pacific bigeye tuna (Thunnus obesus). Fisheries Oceanography 11, 143-155.

Cazelles, B., Chavez, M., Berteaux, D., Ménard F., Vik J.O., Jenouvrier S., Stenseth, N.C., 2008. Wavelet analysis of ecological time series. Oecologia 156, 287-304.

Cazelles, B., Stone, L., 2003. Detection of imperfect population synchrony in an uncertain world. Journal of Animal Ecology 72, 953-968.

Corbineau, A., Rouyer, T., Cazelles, B., Fromentin, J-M., Fonteneau, A., Ménard, F., 2008. Time series analysis of tuna and swordfish catches and climate variability in the Indian Ocean (1968-2003). Aquatic Living Resource 21, 277-285.

Essington, T.E., Schindler, D.E., Olson, R.J., Kitchell, J.F., Boggs, C., Hilborn, R., 2002. Alternative fisheries and the predation rate of yellowfin tuna in the eastern Pacific Ocean. Ecology Application 12, 724-734.

Fonteneau, A., 1997. Atlas of Tropical Tuna Fisheries World Catches and Environment. ORSTOM Editions, Paris, France.

Fonteneau, A., 1998. Panorama de l'exploitation des thonidés dans l'Océan Indien. In: Cayré P., Le Gall, J-Y. (Eds.), Le thon: enjeux et strategies pour l'océan Indien. Paris, ORSTOM, pp. 49-74 (in French).

Fonteneau, A., Richard, N., 2003. Relationship between catch, effort, CPUE and local abundance for non-target species, such as billfishes, caught by Indian Ocean longline fisheries. Marine and Freshwater Research 54, 1-10.

Fromentin, J.M., Myers, R.A., Bjørnstad, O.N, Stenseth, N.C., Gøsæter, J., Christie, H., 2001. Effects of density-dependent and stochastic processes on the regulation of cod populations. Ecology 82, 567-579. 
Gillis, D.M., Peterman, R.M., 1998. Implications of interference among fishing vessels and the ideal free distribution to the interpretation of CPUE. Canadian Journal of Fisheries and Aquatic Sciences 55, 37-46.

Hampton, J., Sibert, J.R., Kleiber, P., Maunder, M., Harley, S.J., 2005. Decline of Pacific tuna populations exaggerated? Nature 434, E1-E2 (28 April 2005). doi:10.1038/nature03581.

Jennings, S., Kaiser, M.J., 1998. The effects of fishing on marine Ecosystems. Advances in Marine Biology 34, 201-352.

Kleiber, P., Maunder, M.N., 2008. Inherent bias in using aggregate CPUE to characterize abundance of fish species assemblages. Fisheries Research 93, 140-145.

Lehodey, P., Bertignac, M., Hampton, J., Lewis, A., Picaut, J., 1997. El Niño Southern Oscillation and tuna in the western Pacific. Nature 389, 715-717.

Lehodey, P., Alheit, J., Barange, M., Baumgartner, T., Beaugrand, G., Drinkwater, K., Fromentin J-M., Hare, S.R., Ottersen, G., Perry, R.I., Roy, C., Van der Lingen, C.D., Werner, F., 2006. Climate variability, fish and fisheries. Journal of Climate 19, 5009-5030.

Longhurst, A.R., 2007. Ecological Geography of the Sea, 2nd edition. Academic Press, Amsterdam, The Netherlands.

Maunder, M.N., Sibert, J.R., Fonteneau, A., Hampton, J. Kleiber, P., Harley, S.J., 2006. Interpreting catch per unit effort data to assess the status of individual stocks and communities. ICES Journal of Marine Science 63, 1373-1385.

Ménard, F., Marsac, F., Bellier, E., Cazelles, B., 2007. Climatic Oscillations and Tuna catch rates in the Indian Ocean: a wavelet approach of time series analysis. Fisheries Oceanography 16, 95-104.

Myers, R.A., Cadigan, N.G., 1993. Density-dependent juvenile mortality in marine demersal fish. Canadian Journal of Fisheries and Aquatic Sciences 50, 1576-1590.

Myers, R.A., Worm, B., 2003. Rapid worldwide depletion of predatory fish communities. Nature 423, 280-283.

Polacheck, T., 2006. Tuna longline catch rates in the Indian Ocean: did industrial fishing result in a $90 \%$ rapid decline in the abundance of large predatory species? Marine Policy 30, 470-482.

Polovina, J.J. 1996. Decadal variation in the trans-Pacific migration of northern bluefin tuna (Thunnus thynnus) coherent with climate-induced change in prey abundance. Fisheries Oceanography 5, 114-119.

Ravier, C., Fromentin, J.-M., 2001. Long-term fluctuations in the eastern Atlantic and Mediterranean bluefin tuna population. ICES Journal of Marine Sciences 58, 1299-1317.

Ravier, C., Fromentin, J.-M. 2004. Are the long-term fluctuations in Atlantic bluefin tuna (Thunnus thynnus) population related to environmental changes? Fisheries Oceanography, 13, 145-160. 
Rouyer, T., Fromentin, J.-M., Ménard, F., Cazelles, B., Briand, K., Pianet, R., Planque B., Stenseth, N.C., 2008a. Complex interplays between population dynamics, environmental forcing and exploitation in fisheries time series. Proceedings of the National Academy of Sciences 105, 5420-5425.

Rouyer, T., Fromentin, J.-M., Stenseth, N.C., Cazelles, B., 2008b. Moving forward with wavelet analysis in ecology. Marine Ecology Progress Series 359, 11-23.

Saji, N.H., Goswami, B.N., Vinayachandran, P.N., Yamagata, T., 1999. A dipole mode in the tropical Indian Ocean. Nature 401, 360-363.

Schott, F.A., McCreary, J.P., 2001. The monsoon circulation of the Indian Ocean. Progress in Oceanography 51, 1-123.

Steele, J.H., 1985. A comparison of terrestrial and marine ecological systems. Nature 313, 355358.

Tomczak, M., Godfrey, J.S., 1994. Regional Oceanography: An Introduction. Pergamon, Oxford, UK.

Torrence, C., Campo, G.P., 1998. A practical guide to wavelet analysis. Bulletin of American Meteorology Society 79, 61-78.

Trenberth, K.E., 1984. Signal versus noise in the Southern Oscillation. Monthly Weather Review 112, 326-332.

Walters, C., 2003. Folly and fantasy in the analysis of spatial catch rate data. Canadian Journal of Fisheries and Aquatic Sciences 60, 1433-1436.

Ward, P., Hindmarsh, S., 2007. An overview of historical changes in the fishing gear and practices of pelagic longliners, with particular reference to Japan's Pacific fleet. Reviews in Fish Biology and Fisheries 17, 501-516.

White, W.B., Cayan, D.R., 2000. A global El Niño - Southern Oscillation wave in surface temperature and pressure and its interdecadal modulation from 1900 to 1994. Journal of Geophysical Research 105, 11223-11242.

\section{Figures}




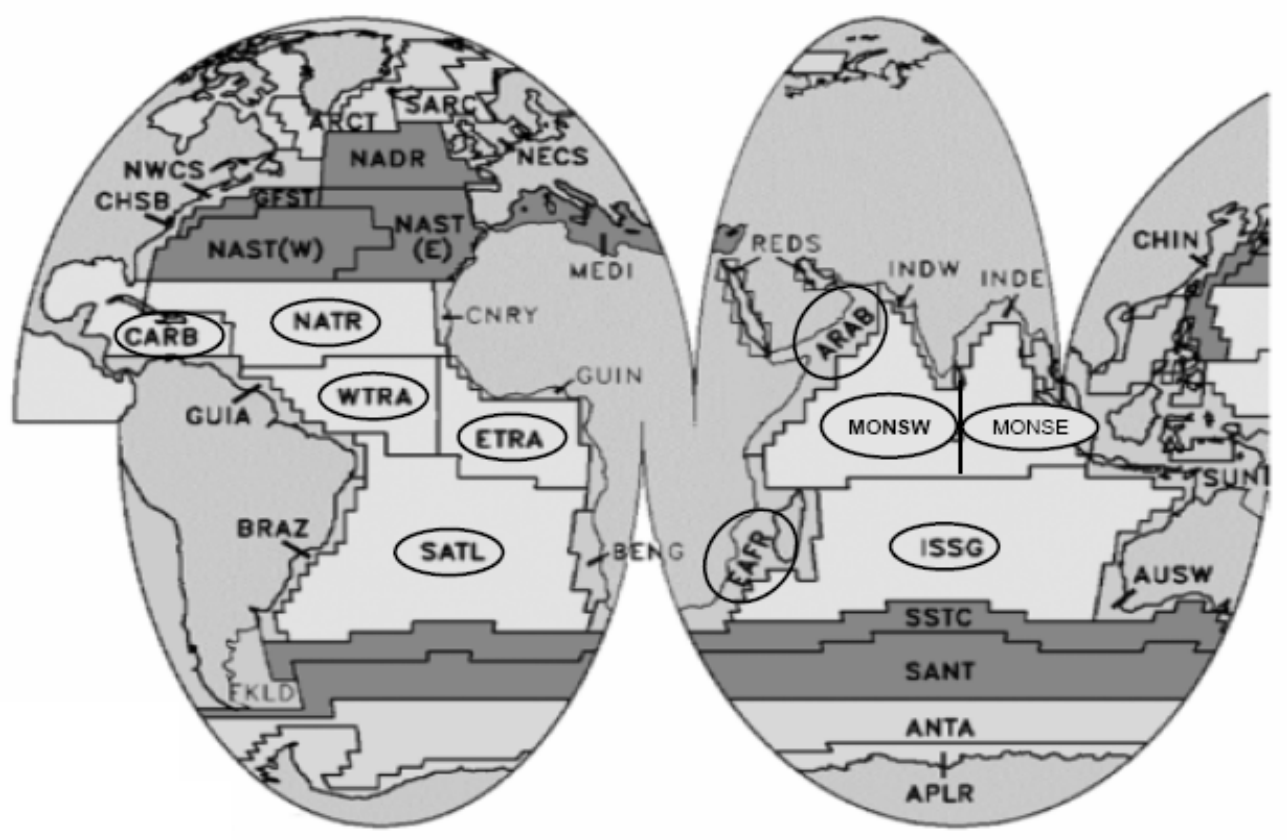

Fig. 1. The biogeographic provinces in the Indian and Atlantic Oceans (adapted from Longhurst, 2007). The ten studied provinces are depicted with circles and include ARAB: Northwestern Arabian Upwelling Province, MONSW: West Indian Monsoon Gyres Province, MONSE: East Indian Monsoon Gyres Province, EAFR: Eastern Africa Coastal Province, ISSG: Indian South Subtropical Gyre Province, NATR: North Atlantic Tropical Gyral Province, CARB: Caribbean Province, WTRA: Western Tropical Atlantic Province, ETRA: Eastern Tropical Atlantic Province, and SATL: South Atlantic Gyral Province. 


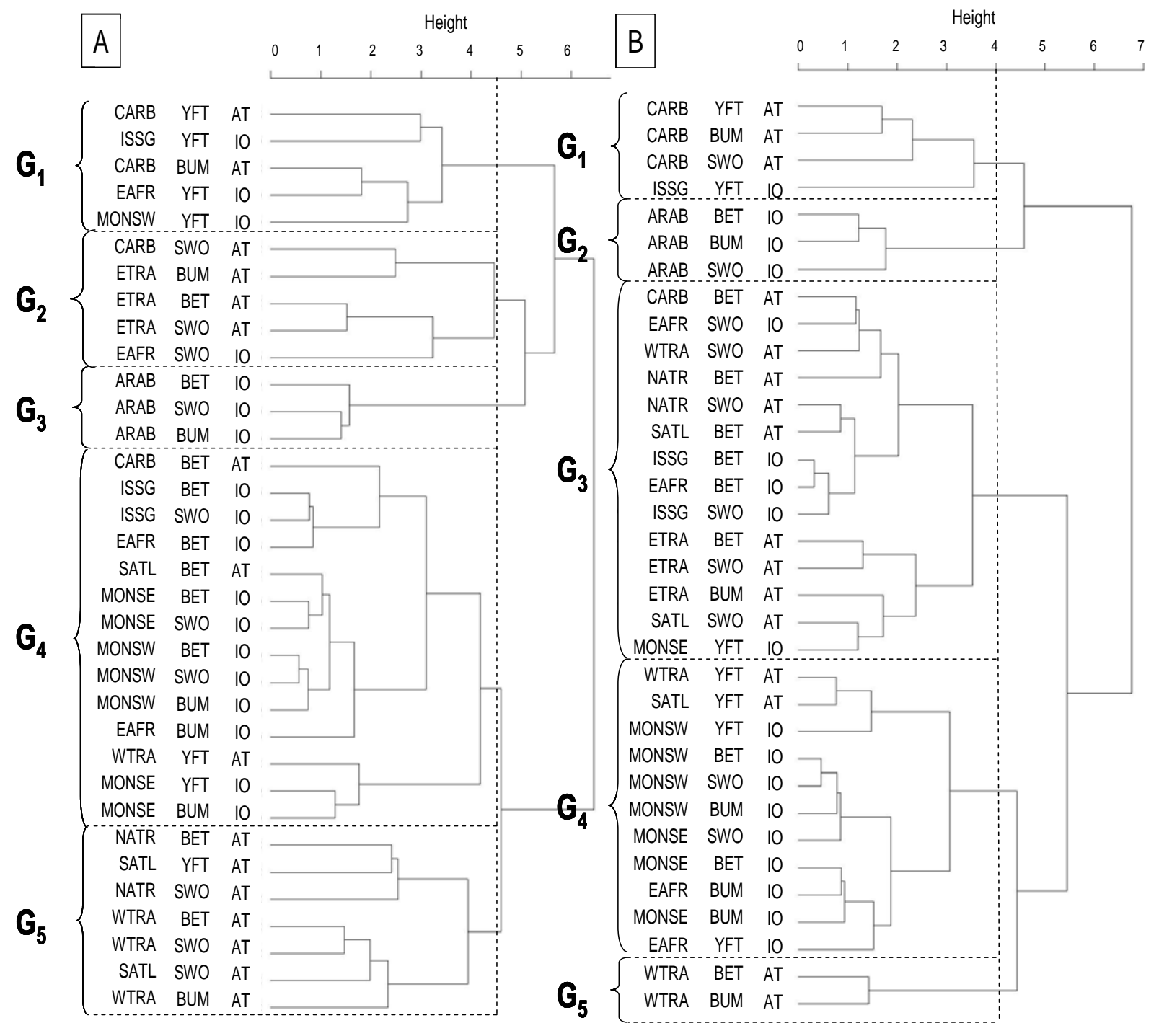

Fig. 2. (A) Cluster dendrogram of the wavelet power spectra (WPS) of the 34 catch time series and (B) cluster dendrogram of the wavelet cross-spectra (WCS) between the 34 catch time series and the SOI, for the time period 1960-2004. The dashed line discriminates the groups $G_{1}, G_{2}, G_{3}, G_{4}$ and $G_{5}$ in both cases and acronyms are as follows: $A T=$ Atlantic Ocean, $I O=$ Indian Ocean, YFT = yellowfin tuna, BET = bigeye tuna, SWO = swordfish, and BUM = blue marlin. MONSW, MONSE, ISSG, ARAB, EAFR, CARB, ETRA, NATR, SATL and WTRA are the biogeographic provinces as described in Section 2.1. Symbols are as in Fig. 1. 


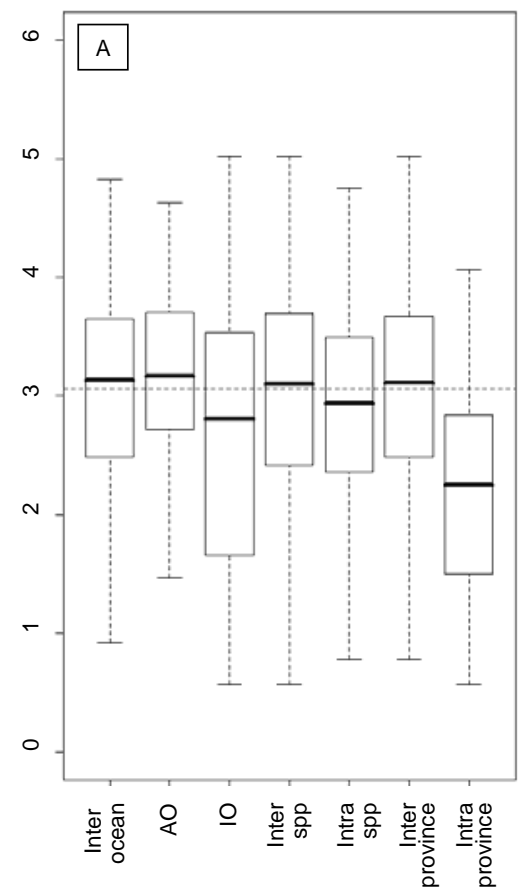

FACTORS

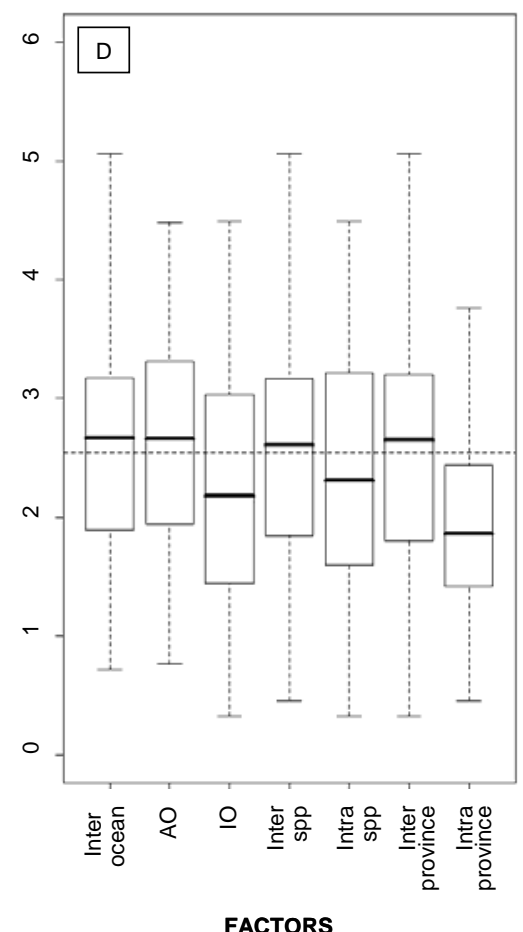

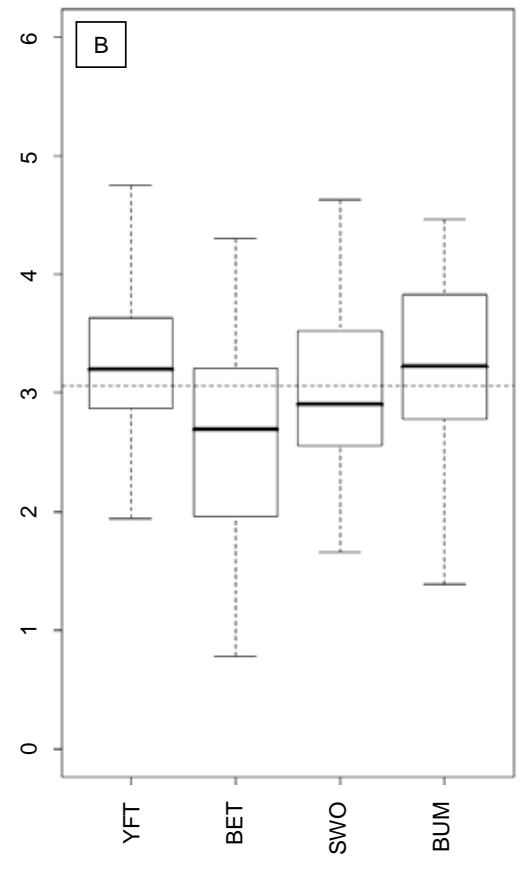

SPECIES MODALITIES

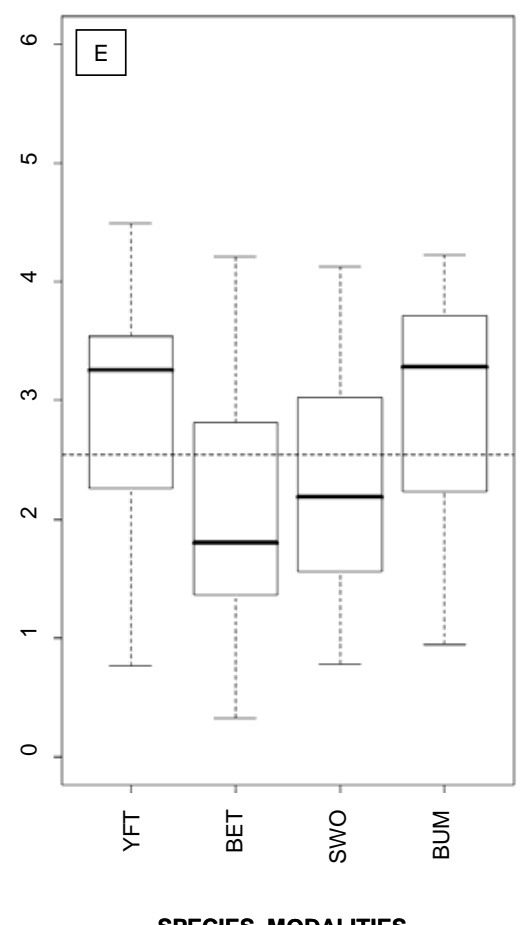

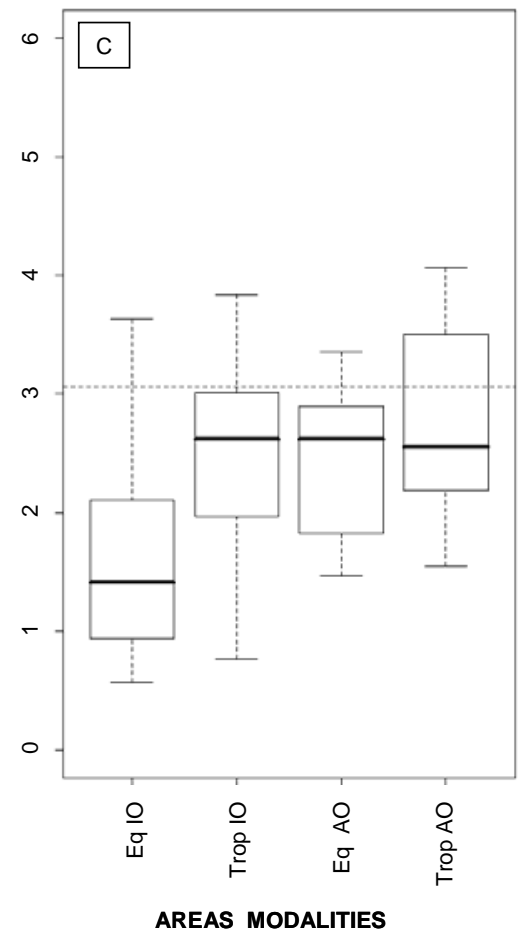

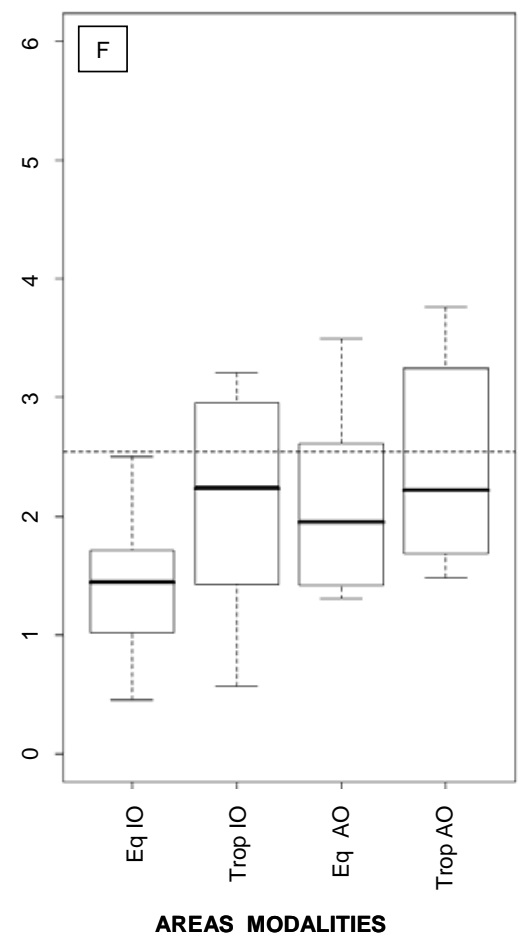

Fig. 3. Boxplots of the distances values by (A) factors based on the wavelet power spectra (WPS); (B) species modalities; (C) areas modalities; (D) factors of the distances based on the wavelet cross spectra (WCS); (E) species modalities; and (F) area modalities. The dotted line 
represents the general median and $\mathrm{AO}=$ Atlantic Ocean, $\mathrm{IO}=$ Indian Ocean, YFT = yellowfin tuna, $\mathrm{BET}=$ bigeye tuna, SWO = swordfish, $\mathrm{BUM}=$ blue marlin, $\mathrm{Eq} \mathrm{IO}=$ Equatorial Indian Ocean (ARAB, MONSW and MONSE provinces), Trop IO = Tropical Indian Ocean (EAFR and ISSG provinces), Eq AO = Equatorial Atlantic Ocean (WTRA and ETRA provinces), and Trop $A O=$ Tropical Atlantic Ocean provinces (NATR, SATL and CARB provinces).
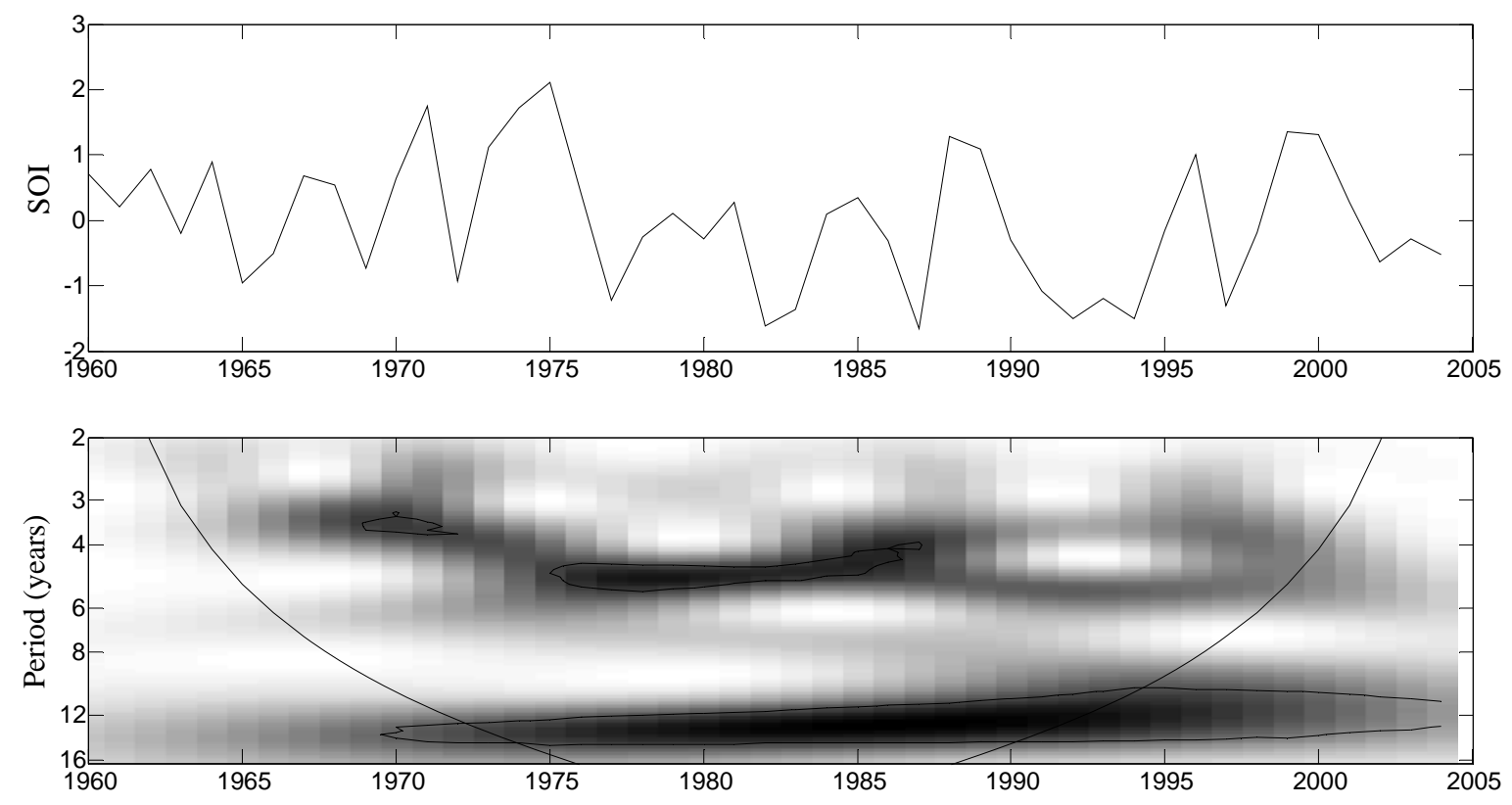

Fig. 4. Wavelet analysis of the SOI time series from 1960 to 2004. Top: standardized SOI signal. Bottom: Wavelet power spectrum of the SOI. High power values are represented in black and low power values in white. The thin solid lines show the $5 \%$ significance level computed from a resampling method based on a Markov process (Cazelles and Stone, 2003). The dotted lines delimit the cone of influence, i.e. the region where the edge effects are present (regions below the cone of influence indicate an important edge effect because of the finite length of the series and therefore values should be interpreted cautiously; Torrence and Compo, 1998). 


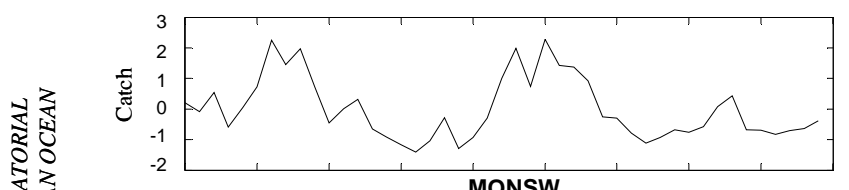

MONSW

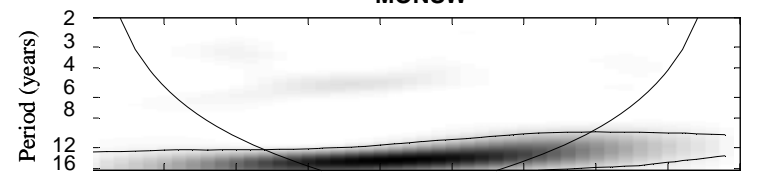

$\begin{array}{llllllllll}1960 & 1965 & 1970 & 1975 & 1980 & 1985 & 1990 & 1995 & 2000 & 2005\end{array}$
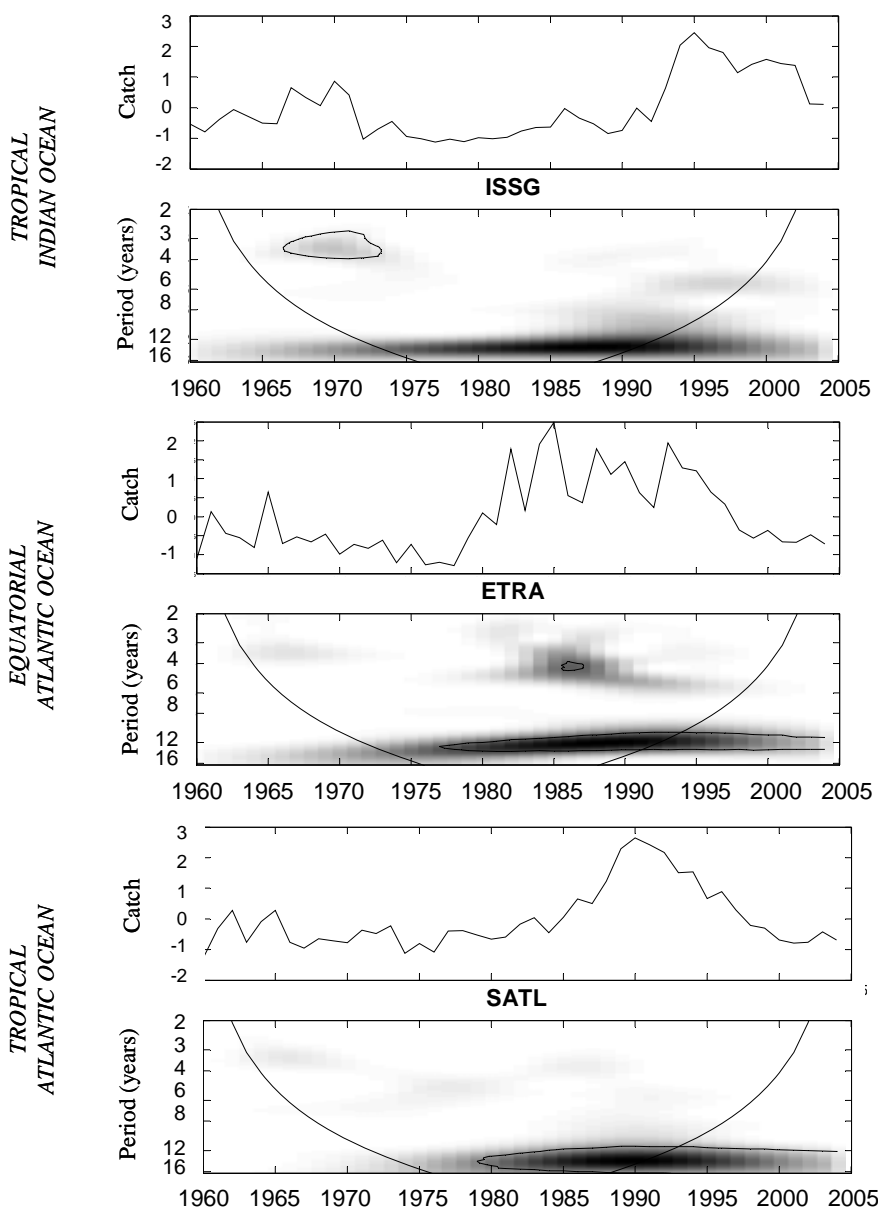
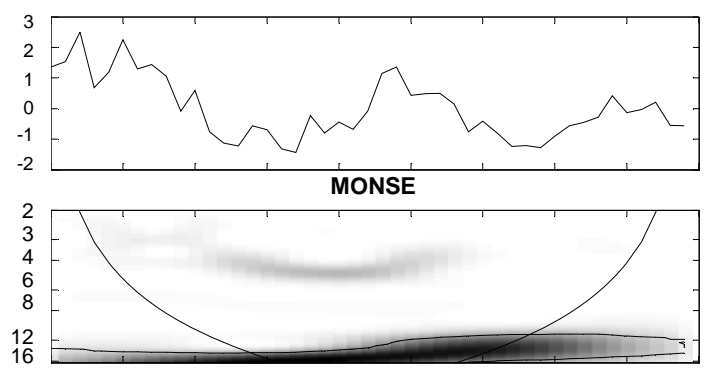

$\begin{array}{llllllllll}1960 & 1965 & 1970 & 1975 & 1980 & 1985 & 1990 & 1995 & 2000 & 2005\end{array}$
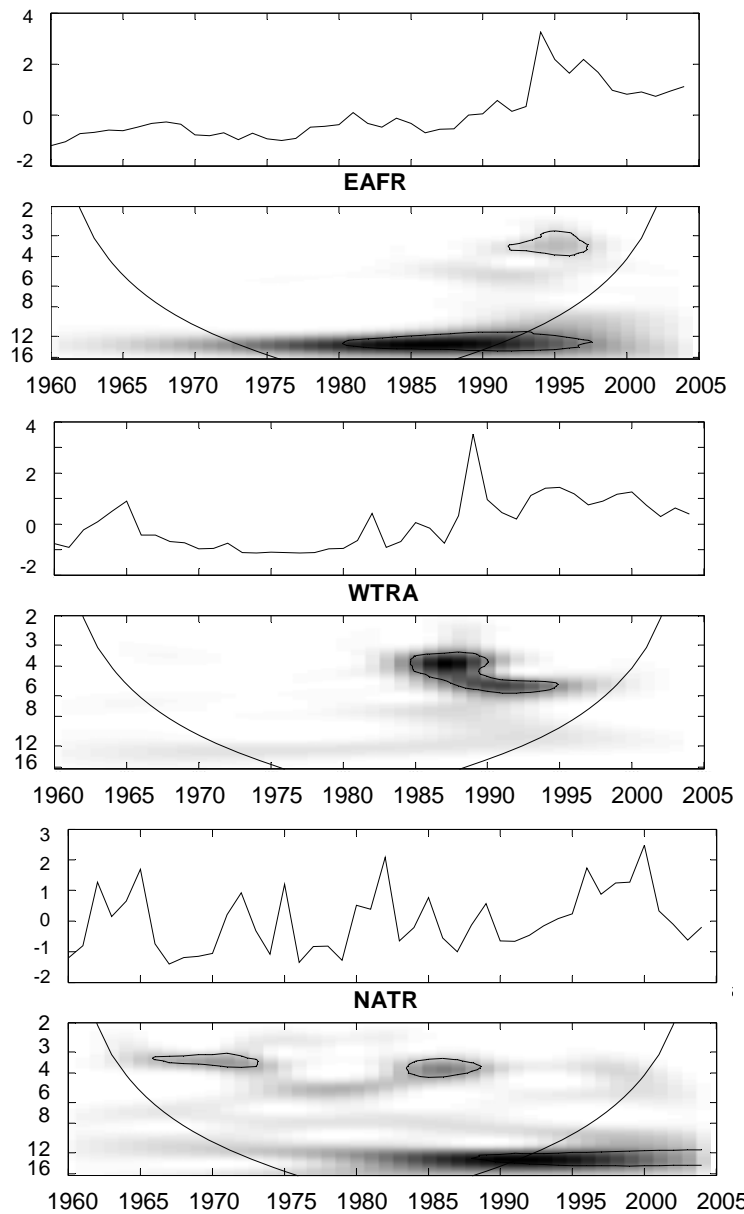

Fig. 5. Bigeye tuna time series and their respective wavelet cross-spectra with the SOI signal in the MONSW, MONSE, ISSG, EAFR, ETRA, WTRA, SATL and NATR provinces. All symbols and values are as in Figs. 1 and 4. 